\title{
Differential involvement of dopamine D1 receptor and MEK signaling pathway in the ventromedial prefrontal cortex in consolidation and reconsolidation of recognition memory
}

\author{
Mouna Maroun ${ }^{1}$ and Irit Akirav ${ }^{2,3}$ \\ ${ }^{1}$ Department of Neurobiology and Ethology, University of Haifa, Haifa 31905, Israel; ${ }^{2}$ Department of Psychology, University \\ of Haifa, Haifa 31905, Israel
}

\begin{abstract}
We investigated MEK and Dl receptors in the ventromedial prefrontal cortex (vmPFC) in consolidation and reconsolidation of recognition memory in rats nonhabituated to the experimental context $(\mathrm{NH})$ or with reduced arousal due to extensive prior habituation $(\mathrm{H})$. The Dl receptor antagonist enhanced consolidation and impaired reconsolidation in $\mathrm{NH}$ but impaired consolidation with no effect on reconsolidation in $\mathrm{H}$. The D1 receptor agonist had no effect on consolidation in either $\mathrm{H}$ or $\mathrm{NH}$ but impaired reconsolidation in both groups. The MEK inhibitor impaired consolidation and reconsolidation, regardless of arousal. Thus, vmPFC DI receptors and MEK show differential involvement in memory and arousal.
\end{abstract}

Evidence indicates that the prefrontal cortex (PFC) plays an important role in long-term recognition memory processes (Meunier et al. 1997; Ragozzino et al. 2002). Indeed, we have recently shown that both protein synthesis and NMDA receptors are required for consolidation and reconsolidation of recognition memory in the ventromedial PFC (vmPFC) (Akirav and Maroun 2006).

Dopamine D1 receptors play an important role in prefrontal function, such as working memory, and there is evidence that dopamine D1 receptor activity can modulate plasticity (Gurden et al. 2000; Chen et al. 2007; Nagai et al. 2007; Rinaldi et al. 2007; Vijayraghavan et al. 2007). It has been suggested that the dopamine D1 receptor extracellular signal-regulated kinase (ERK1/2) signaling pathway in the PFC is critically involved in molecular adaptations that are necessary for long-term behavioral and neuronal plasticity (Nagai et al. 2007). The phosphorylation of ERK has been shown to be a correlate for plasticity (for review, see Sweatt 2004) and long-term memory for taste (Berman et al. 1998), fear conditioning (Schafe et al. 2000), and spatial tasks (Blum et al. 1999; Hebert and Dash 2002). Nagai et al. (2007) have found that dopamine D1 receptors regulate protein synthesis-dependent long-term recognition memory via ERK in the PFC.

Exposure to stress is known to precipitate many neuropsychiatric disorders such as depression and schizophrenia (Mazure 1995). These disorders involve memory deficits caused by PFC dysfunction (Mattes 1980; Weinberger et al. 1986; Deutch 1993; Fibiger 1995). Experimental evidence has shown that acute mild stressful stimuli such as exposure to novelty increases dopamine (DA) and dopamine metabolism in the PFC, producing working memory impairment that can be blocked by agents that prevent the increase in DA turnover (Murphy et al. 1996; Enrico et al. 1998; Takahata and Moghaddam 1998; Ihalainen et al. 1999; Feenstra et al. 2000; Del Arco and Mora 2001).

\footnotetext{
${ }^{3}$ Corresponding author. E-mail irit.akirav@gmail.com or iakirav@psy.haifa.ac.il; fax 972-48288268.
}

Article is online at http://www.learnmem.org/cgi/doi/10.1101//m.1245009.
We have recently shown that novelty or familiarity with the experimental arena, which differentially affects the arousal level of the rat, also has a differential effect on consolidation and reconsolidation of object recognition memory. Specifically, learning was tested under two arousal conditions: no previous habituation to the experimental context (high novelty stress/arousal level) or extensive prior habituation to the experimental context (reduced novelty stress/arousal level). We found that the nonhabituated aroused rats were impaired when consolidation was examined, but their memory was intact following reactivation of the memory trace. Furthermore, microinjection of a beta-adrenergic blocker to the basolateral amygdala (BLA) immediately after the training resulted in intact retrieval (Maroun and Akirav 2007).

In this study, we investigated the involvement of dopamine D1 receptor-MEK signaling pathway in the vmPFC in consolidation and reconsolidation of recognition memory under two arousal conditions: high (no previous habituation) or low (extensive prior habituation).

The subjects were 138 male Sprague-Dawley rats ( $~ 60 \mathrm{~d}$ old, 250-300 g), caged individually at $22 \pm 2^{\circ} \mathrm{C}$ under 12 -h light/12-h dark cycles. All tests were performed between 10 a.m. and 4 p.m. The experiments were approved by the University of Haifa Ethics and Animal Care Committee, and adequate measures were taken to minimize pain or discomfort in accordance with the guidelines laid down by the NIH in the U.S. regarding the care and use of animals for experimental procedures.

The object recognition task is described in Maroun and Akirav (2007). Briefly, the objects were located in squared black open field $(50 \times 50 \times 50 \mathrm{~cm})$ under dim light and were fixed to the floor of the open field arena, $10 \mathrm{~cm}$ from the walls. The objects used were children's toys. The open field and the objects were thoroughly cleaned between trials with odorous clean wipes.

Exploration was defined as sniffing or touching the object with the nose and/or forepaws. A discrimination index calculated for each animal was expressed as $\mathrm{TN} /(\mathrm{TN}+\mathrm{TF})[\mathrm{TF}=$ time spent exploring the familiar object; $\mathrm{TN}=$ time spent exploring the novel object]. Intact recognition memory in the test phase is reflected in a discrimination index higher than 0.5 , which implies greater 


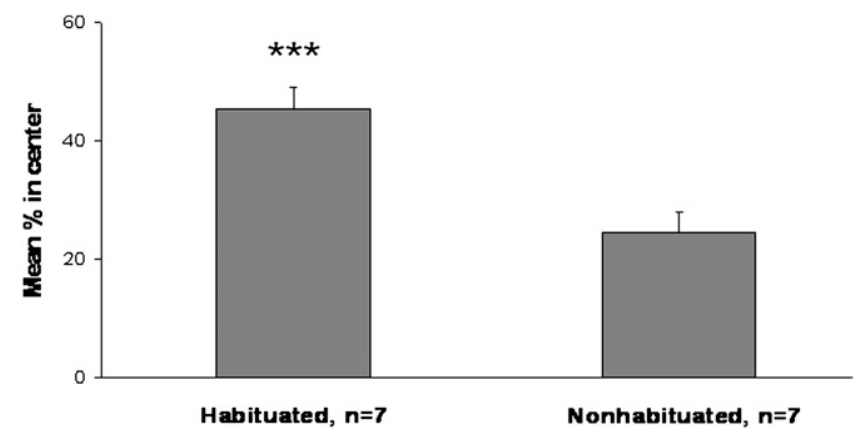

Figure 1. Nonhabituated rats spend less time in the center of the open field. Nonhabituated rats spent significantly less time exploring the central areas as compared with the habituated rats (***, $P<0.001$ ), suggesting higher anxiety levels in the nonhabituated rats.

exploration of the novel object. T-test, ANOVA, and the least significant difference multiple comparison test were used to assess behavioral data.

About half of the rats were habituated to the experimental apparatus by allowing them to explore it for $5 \mathrm{~min}$ twice a day for $4 \mathrm{~d}$ before the experiment was performed (habituated, or $\mathrm{H}$ ). No object was placed inside the arena during habituation. The other half were not habituated to the experimental apparatus, only handled once a day for $2 \mathrm{~d}$ in their home cage (nonhabituated, or $\mathrm{NH}$ ). We assessed the level of arousal in habituated and nonhabituated rats using the open-field test, with no objects. Figure 1 shows that NH rats spent significantly less time exploring the central areas as compared with the habituated rats $\left(t_{(12)}=5.2, P<0.001\right)$, which suggests higher anxiety levels in the nonhabituated rats.

To test whether D1 receptors and MEK pathway are necessary for consolidation, on day 1 (sample phase), each rat was placed in the open field arena and allowed to explore two different objects for 5 min (A and B). Drugs or vehicle were microinjected to the vmPFC immediately following the sample phase. On day 2 (test phase), the rats were presented with a duplicate of an object from the sample trial and a novel object (A and C) for $5 \mathrm{~min}$. All figures indicate discrimination index in the test phase.

To test whether D1 receptors and MEK pathway are necessary for reconsolidation, on day 1 (sample phase), each rat was placed in the open field arena and allowed to explore two different objects for 5 min (A and B). On day 2 (reactivation), they were exposed to the same two sample objects for a 5 -min period to reactivate the memory trace (A and B). Drugs or vehicle were microinjected to the vmPFC immediately following the reactivation phase. On day 3 (test phase), the rats were presented with a duplicate of an object from the sample trial and a novel object (A and C) for 5 min. All figures show discrimination index in the test phase.

Microinjection was performed via chronically implanted cannulae. Rats were implanted bilaterally with a guide stainless cannula (23 gauge) aimed at the infralimbic (IL) and prelimbic areas (PL) (together they compose the vmPFC; anteroposterior, $+3 \mathrm{~mm}$ relative to bregma; lateral, $\pm 0.5 \mathrm{~mm}$; ventral, $-5 \mathrm{~mm}$ ). Animals were allowed 1 wk to recuperate. For microinjection, a 28gauge injection cannula, extending $1 \mathrm{~mm}$ from the tip of the guide cannula, was inserted. The injection cannula was connected via PE20 tubing to a Hamilton microsyringe driven by a microinjection pump (CMA/100; Carnegie Medicin). Microinjection was performed bilaterally in a $0.5-\mu \mathrm{L}$ volume per hemisphere delivered over $1 \mathrm{~min}$. The injection cannula was left in position before withdrawal for an additional $1 \mathrm{~min}$ to minimize dragging of the injected liquid along the injection tract. The dopamine D1 receptors antagonist SCH 23390 hydrochloride (SCH; $8 \mu \mathrm{g} / 0.5$ $\mu \mathrm{l})$ and agonist SKF (SKF; 10ng/0.5 $\mu \mathrm{l}$ ) were dissolved in saline
(0.9\%) (Sigma). The MEK inhibitor PD 98059 (PD; Sigma) $(50 \mu \mathrm{M} /$ $0.5 \mu \mathrm{l})$ was dissolved in $0.5 \%$ DMSO and saline, which was also used as control.

At the completion of the behavioral experiments animals were deeply anesthetized and microinjected into the vmPFC with $0.5 \mu \mathrm{L}$ of India ink. Frozen brain slices $(60 \mu \mathrm{m})$ were examined under a light microscope following Nissl staining to verify the cannula location. Placements of the cannulae were found to be correct in all injected rats (Fig. 2),

To examine the effects of DA and MEK inhibition on consolidation of the recognition task, eight groups of habituated and nonhabituated rats were exposed to the sample phase on day 1. Immediately afterward, they were microinjected into the vmPFC with vehicle or the drugs (Fig. 3A). A two-way ANOVA conducted on discrimination index on day 2 (arousal: habituated/ nonhabituated; drug: drug/vehicle) revealed significant effects of the drug $\left(F_{(3,59)}=10.304, P<0.0001\right)$ but not arousal $\left(F_{(1,59)}=\right.$ 0.608 , NS). The interaction between arousal and drug $\left(F_{(3,59)}=\right.$ $16.044, P<0.0001)$ was significant, indicating that the drugs had different effects in the different arousal levels. Further analyzing the data showed a significant difference between the groups in discrimination index in the test on day $2\left(F_{(7,59)}=14.694, P<\right.$ 0.0001). Post-hoc comparisons revealed that, in the habituated group, both $\mathrm{PD}$ and $\mathrm{SCH}$ microinjected rats spent significantly less time exploring the new object as compared with the control (PD: $P<0.0001$; SCH: $P<0.001)$. In contrast, the SKF group was not different from the control group.

In the nonhabituated groups, $\mathrm{SCH}$ microinjected rats spent significantly more time exploring the new object as compared with the control, the PD, and the SKF groups (control: $P<0.001$; PD: $P<0.001$; SKF: $P<0.0001)$, indicating that $\mathrm{SCH}$-treated rats had intact long-term recognition memory. Further, there was no significant difference between the groups in discrimination index during the sample phase (day 1 ; data not shown) $\left(F_{(7,59)}=1.3\right.$, NS).

A significant difference in total exploration time was found between the $\mathrm{H}$ and the $\mathrm{NH}$ groups $\left(t_{(65)}=3.75 ; P<0.001\right)$, showing that the $\mathrm{NH}$ animals spent significantly more time exploring the objects compared with the $\mathrm{H}$ animals. This difference in exploration time between $\mathrm{H}$ and $\mathrm{NH}$ animals is consistent with our previous findings (Maroun and Akirav 2007) and with reports

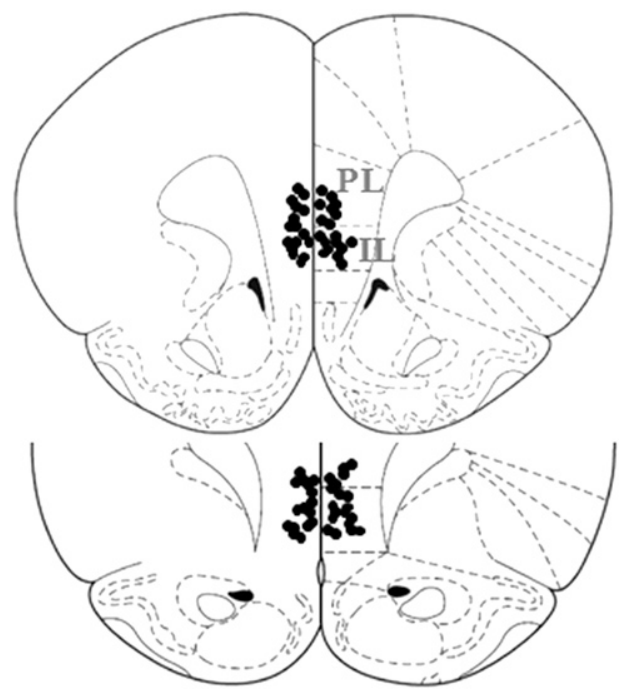

Figure 2. Schematic drawing of infralimbic (IL) and prelimbic (PL) injector tip positions. Shown is a coronal view at position 3.20 and 2.70 $\mathrm{mm}$ anterior to bregma. (Adapted from Paxinos and Watson 1986 with permission from Elsevier (C) 1986.) 

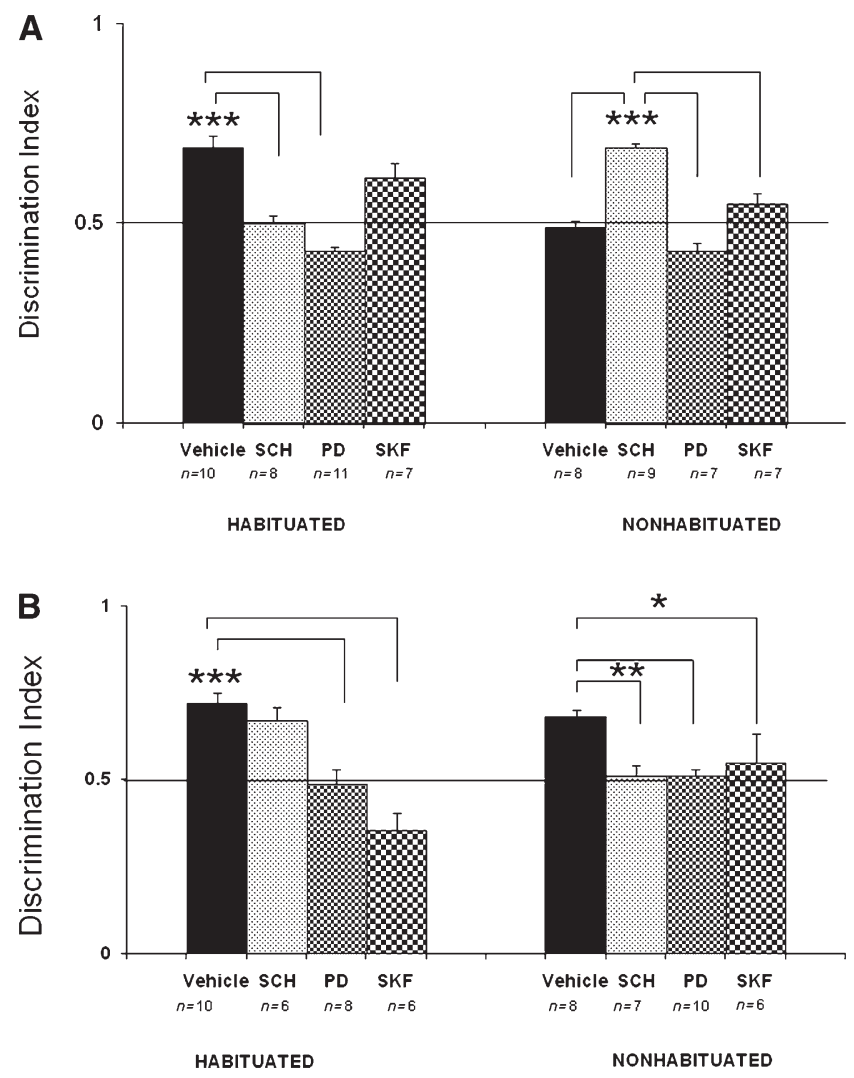

Figure 3. Differential effect of D1 activation and blockade and MEK inhibition on consolidation and reconsolidation of recognition memory in habituated vs. nonhabituated rats $(A)$. In habituated rats, D1 and MEK inhibition ( $\mathrm{SCH}$ and $\mathrm{PD}$, respectively) impaired consolidation of recognition memory compared with the vehicle group $(* * *, \mathrm{SCH}: P<0.001$; PD: $P<0.0001$ ) whereas D1 activation (SKF) had no effect. In nonhabituated rats, SCH facilitated consolidation compared with the vehicle group (***, $P<0.001)$. No significant difference was found between the vehicle, PD, and SKF groups. (B). In habituated rats, MEK inhibition (PD) and D1 activation (SKF) impaired reconsolidation of recognition memory compared with the vehicle group (***, PD: $P<0.001$; SKF: $P<0.0001$ ), whereas D1 blockade ( $\mathrm{SCH}$ ) had no effect. However, in nonhabituated rats, all drug treatments impaired reconsolidation compared with the vehicle group (**, SCH: $P<0.01$; PD: $P<0.01 ;{ }^{*}, \mathrm{SKF}: P<0.05$ ).

suggesting a decrease in exploratory activity as a function of repeated exposure to the same environment (Hui et al. 2005).

To test the consolidation window of MEK inhibition in $\mathrm{H}$ rats, we microinjected PD $3 \mathrm{~h}$ following the sample phase. Our results show that $3 \mathrm{~h}$ following acquisition of the task, the memory trace is no longer susceptible to disruption by PD (Vehicle: $0.67 \pm 0.03$, $n=5$; PD: $0.63 \pm 0.04, n=5$ ). This suggests that the effects of the drugs on consolidation cannot be attributed to neurotoxicity or general impairment.

To examine the effects of DA and MEK inhibition on reconsolidation of the recognition task, eight groups of habituated and nonhabituated rats were exposed to the sample phase on day 1. Twenty-four hours afterward, they were microinjected to the vmPFC with vehicle or the drugs following reactivation (Fig. 3B). A two-way ANOVA conducted on discrimination index on day 3 revealed significant effects of the drug $\left(F_{(3,53)}=15.08, P<0.0001\right)$ and the interaction between arousal and drug $\left(F_{(3,53)}=5.89, P=\right.$ $0.001)$ but not of the arousal $\left(F_{(1,53)}=0.001, N S\right)$. Further analyzing the data showed a significant difference between the groups in discrimination index in the test on day $3\left(F_{(7,53)}=9.273, P<\right.$ 0.0001).
Post-hoc comparisons revealed that in the habituated group, both PD and SKF microinjected rats spent significantly less time exploring the new object as compared with the control rats (PD: $P<0.001$; SKF: $P<0.0001)$. In contrast, no difference was observed between the $\mathrm{SCH}$-treated rats and the control group. In the nonhabituated groups, the drug-treated rats spent significantly less time exploring the new object as compared with the control group (PD: $P<0.01$; SCH: $P<0.01$; SKF: $P<0.05$ ). Further, there was no significant difference between the groups in discrimination index during the sample $\left(F_{(7,53)}=1.086\right.$, NS) (day 1 ; data not shown) or the reactivation phase $\left(F_{(7,53)}=1.576\right.$, NS) (day 2; data not shown).

We examined the effects of post-training activation and blockade of D1 receptors and MEK blockade in the vmPFC on consolidation and reconsolidation of object recognition memory in rats with either low or high level of arousal due to prior habituation/no habituation to the experimental arena. The D1 receptor antagonist $\mathrm{SCH}$ impaired 24-h retention in rats that were well habituated before the training, corroborating other reports showing that D1 receptors are important for the consolidation of PFC-dependent tasks (Hotte et al. 2005; Izquierdo et al. 2007; Nagai et al. 2007). However, D1 blockade enhanced 24-h retention in rats that were not previously habituated to the experimental context. An opposed effect of the arousal level was observed when the memory trace was reactivated. Specifically, D1 blockade did not affect reconsolidation in rats that were habituated before the training but impaired reconsolidation in rats that were not previously habituated to the experimental context. Taken together, these findings suggest a differential involvement of D1 receptors in the vmPFC in memory consolidation and reconsolidation of object recognition and that these effects on memory depend on the level of emotional arousal associated with initial encoding. In contrast, $\mathrm{H}$ and $\mathrm{NH}$ rats were microinjected with the D1 receptor agonist SKF showed intact and impaired performance, respectively, on the 24 -h retention test. However, when the memory trace was reactivated, D1 activation impaired reconsolidation in both $\mathrm{H}$ and $\mathrm{NH}$ rats.

Finally, microinjecting the MEK inhibitor PD to the vmPFC post-training resulted in impaired consolidation and reconsolidation in both $\mathrm{H}$ and $\mathrm{NH}$ rats. These findings are consistent with those of several reports showing that activation of the MEK signaling cascade is necessary for consolidation of different forms of long-term memory (Brambilla et al. 1997; Atkins et al. 1998; Berman et al. 1998; Blum et al. 1999; Kelleher et al. 2004) including object recognition (Bozon et al. 2003; Kelly et al. 2003) and for memory reconsolidation (Kelly et al. 2003; Duvarci et al. 2005; Cestari et al. 2006; Nagai et al. 2007).

It has been suggested that working memory performance is optimized when there is a normal range of dopamine transmission in the PFC that can be described as an "inverted-U" relationship (Zahrt et al. 1997; Phillips et al. 2004; Anstrom and Woodward 2005; Williams and Castner 2006). Stress and novelty that increase extracellular and DA turnover may drive release-dominated systems such as the medial PFC out of optimal ranges and result in impaired performance in a memory task. Indeed, exposure to stress that induced increased DA transmission was reported to impair certain types of PFC-dependent memory tasks, such as working memory. These impairments were reversed by agents that prevented the increase in DA turnover (Murphy et al. 1996; Arnsten and Goldman-Rakic 1998). Stress-induced dopamine release is partly influenced by circulating glucocorticoid levels (Piazza et al. 1996; Rouge-Pont et al. 1998; Marinelli and Piazza 2002), which also increase in response to stress. It has been reported (Okuda et al. 2004) that nonhabituated animals have higher levels of corticosterone than habituated animals corroborating with our results showing that nonhabituated animals are 
more stressed than habituated (Maroun and Akirav 2007). Additionally, post-training corticosterone injections (Okuda et al. 2004) or exposure to the elevated platform stressor (Maroun and Akirav 2007) enhanced the performance of the $\mathrm{NH}$ rats in a test given $24 \mathrm{~h}$ after training.

In line with this, we suggest that blocking D1 receptors in the $\mathrm{mPFC}$ in NH rats affects the inverted U-shaped function so that $\mathrm{SCH}$ restores performance in the consolidation of recognition memory of $\mathrm{NH}$ rats but impairs consolidation in $\mathrm{H}$ animals. In $\mathrm{NH}$ rats the D1 blockade optimizes the levels of DA and in $\mathrm{H}$ it impairs the normal range of DA transmission. Similarly, it has been shown that pretreatment with the D1 antagonist SCH may block stressrelated deleterious cognitive consequences (Arnsten and GoldmanRakic 1998). Hence, D1 receptor agonist and antagonist were found to have opposite effects on consolidation; $\mathrm{H}$ rats showed impaired and intact performance with SCH and SKF, respectively. $\mathrm{NH}$ rats show impaired and intact performance with SKF and $\mathrm{SCH}$, respectively. This is in accordance with the inverse U-shaped curve of D1 receptor functions in which D1 agonist rats show good performance with low arousal $(\mathrm{H})$ and impaired with high arousal (NH). Hence, low DA levels (SCH to H rats) or high DA levels ( $\mathrm{NH}$ vehicle and $\mathrm{NH}$ SKF) would result in impaired performance. However, intermediate levels of DA (H vehicle, H SKF, NH SCH) would result in intact performance.

This is in accordance with a recent study by Herold et al. (2008) that has shown that in pigeons performing a working memory task D1 agonist to the avian functional analog of the PFC was able to improve or to decrease performance during low or strong performance periods, respectively.

Yet, another explanation for the effect on consolidation may be that $\mathrm{SCH}$ may enhance memory consolidation in animals with otherwise poor memory and impair memory if the controls already show good memory. Indeed, there is data suggesting that D1 receptor activity can exert differential effects over PFC function, depending on the strength of the memory trace (Floresco and Phillips 2001).

The differential effects of the D1 antagonist and agonist on reconsolidation further support previous arguments suggesting that consolidation and reconsolidation may be distinct memory processes although they might share mechanisms and even functions (Nader et al. 2000; Sara 2000; Dudai and Eisenberg 2004; Alberini 2005; Dudai 2006). The data demonstrate that consolidation and reconsolidation of recognition memory in the PFC are differentially influenced by D1 related mechanisms and this may suggest that these are two distinct memory processes. Yet, another possibility is that consolidation and reconsolidation are similar processes with different dopaminergic dose response curves. According to these hypotheses, using different doses of D1 activation and blockade for consolidation and reconsolidation may result in a similar outcome.

This study suggests the existence of a close relationship between cortical dopaminergic neurotransmission and learning under emotional conditions and may be important to our understanding of the role of D1 receptors in the PFC in stress-related disorders.

\section{Acknowledgment}

This work was supported by The Ebelin and Gerd Bucerius ZEIT Foundation to M.M.

\section{References}

Akirav, I. and Maroun, M. 2006. Ventromedial prefrontal cortex is obligatory for consolidation and reconsolidation of object recognition memory. Cereb. Cortex 16: 1759-1765.
Alberini, C.M. 2005. Mechanisms of memory stabilization: Are consolidation and reconsolidation similar or distinct processes? Trends Neurosci. 28: 51-56.

Anstrom, K.K. and Woodward, D.J. 2005. Restraint increases dopaminergic burst firing in awake rats. Neuropsychopharmacology 30: 1832-1840.

Arnsten, A.F. and Goldman-Rakic, P.S. 1998. Noise stress impairs prefrontal cortical cognitive function in monkeys. Arch. Gen. Psychiatry 55: 362368.

Atkins, C.M., Selcher, J.C., Petraitis, J.J., Trzaskos, J.M., and Sweatt, J.D. 1998. The MAPK cascade is required for mammalian associative learning. Nat. Neurosci. 1: 602-609.

Berman, D.E., Hazvi, S., Rosenblum, K., Seger, R., and Dudai, Y. 1998 Specific and differential activation of mitogen-activated protein kinase cascades by unfamiliar taste in the insular cortex of the behaving rat. $J$. Neurosci. 18: 10037-10044.

Blum, S., Moore, A.N., Adams, F., and Dash, P.K. 1999. A mitogen-activated protein kinase cascade in the CA1/CA2 subfield of the dorsal hippocampus is essential for long-term spatial memory. J. Neurosci. 19: 3535-3544.

Bozon, B., Davis, S., and Laroche, S. 2003. A requirement for the immediate early gene zif268 in reconsolidation of recognition memory after retrieval. Neuron 40: 695-701.

Brambilla, R., Gnesutta, N., Minichiello, L., White, G., Roylance, A.J., Herron, C.E., Ramsey, M., Wolfer, D.P., Cestari, V., Rossi-Arnaud, C., et al. 1997. A role for the Ras signalling pathway in synaptic transmission and longterm memory. Nature 390: 281-286.

Cestari, V., Costanzi, M., Castellano, C., and Rossi-Arnaud, C. 2006. A role for ERK2 in reconsolidation of fear memories in mice. Neurobiol. Learn. Mem. 86: 133-143.

Chen, L., Bohanick, J.D., Nishihara, M., Seamans, J.K., and Yang, C.R. 2007 Dopamine D1/5 receptor-mediated long-term potentiation of intrinsic excitability in rat prefrontal cortical neurons: Ca2+-dependent intracellular signaling. J. Neurophysiol. 97: 2448-2464.

Del Arco, A. and Mora, F. 2001. Dopamine release in the prefrontal cortex during stress is reduced by the local activation of glutamate receptors. Brain Res. Bull. 56: 125-130.

Deutch, A.Y. 1993. Prefrontal cortical dopamine systems and the elaboration of functional corticostriatal circuits: Implications for schizophrenia and Parkinson's disease. J. Neural Transm. 91: 197-221.

Dudai, Y. 2006. Reconsolidation: The advantage of being refocused. Curr. Opin. Neurobiol. 16: 174-178.

Dudai, Y. and Eisenberg, M. 2004. Rites of passage of the engram: Reconsolidation and the lingering consolidation hypothesis. Neuron 44: $93-100$.

Duvarci, S., Nader, K., and LeDoux, J.E. 2005. Activation of extracellular signal-regulated kinase-mitogen-activated protein kinase cascade in the amygdala is required for memory reconsolidation of auditory fear conditioning. Eur. J. Neurosci. 21: 283-289.

Enrico, P., Bouma, M., De Vries, J.B., and Westerink, B.H.C. 1998. The role of afferents to the ventral tegmental area in the handling stress-induced increase in the release of dopamine in the medial prefrontal cortex: A dual-probe microdialysis study in the rat brain. Brain Res. 779: 205213.

Feenstra, G.P., Botterblom, M.H.A., and Mastenbroek, S. 2000. Dopamine and noradrenaline efflux in the prefrontal cortex in the light and dark period: Effects of novelty and handling and comparison to the nucleus accumbens. Neuroscience 100: 741-748.

Fibiger, H.C. 1995. Neurobiology of depression: Focus on dopamine. Adv. Biochem. Psychopharmacol. 49: 1-17.

Floresco, S.B. and Phillips, A.G. 2001. Delay-dependent modulation of memory retrieval infusion of a dopamine D1 agonist into the rat medial prefrontal cortex. Behav. Neurosci. 115: 934-939.

Gurden, H., Takita, M., and Jay, T.M. 2000. Essential role of D1 but not D2 receptors in the NMDA receptor-dependent long-term potentiation at hippocampal-prefrontal cortex synapses in vivo. J. Neurosci. 20: RC106.

Hebert, A.E. and Dash, P.K. 2002. Extracellular signal-regulated kinase activity in the entorhinal cortex is necessary for long-term spatial memory. Learn. Mem. 9: 156-166.

Herold, C., Diekampa, B., and Güntürküna, O. 2008. Stimulation of dopamine D1 receptors in the avian fronto-striatal system adjusts daily cognitive fluctuations. Behav. Brain Res. 194: 223-229.

Hotte, M., Naudon, L., and Jay, T.M. 2005. Modulation of recognition and temporal order memory retrieval by dopamine D1 receptor in rats. Neurobiol. Learn. Mem. 84: 85-92.

Hui, Z., Guang-Yu, M., Chong-Tao, X., Quan, Y., and Xiao-Hu, X. 2005. Phenytoin reverses the chronic stress-induced impairment of memory consolidation for water maze training and depression of LTP in rat hippocampal CA1 region, but does not affect motor activity. Brain Res. Cogn. Brain Res. 24: 380-385.

Ihalainen, J.A., Riekkinen Jr., P., and Feenstra, M.G. 1999. Comparison of dopamine and noradrenaline release in mouse prefrontal cortex, 
striatum and hippocampus using microdialysis. Neurosci. Lett. 277: 7174.

Izquierdo, L.A., Barros, D.M., da Costa, J.C., Furini, C., Zinn, C., Cammarota, M., Bevilaqua, L.R., and Izquierdo, I. 2007. A link between role of two prefrontal areas in immediate memory and in long-term memory consolidation. Neurobiol. Learn. Mem. 88: 160-166.

Kelleher, 3rd, R.J., Govindarajan, A., Jung, H.Y., Kang, H., and Tonegawa, S. 2004. Translational control by MAPK signaling in long-term synaptic plasticity and memory. Cell 116: 467-479.

Kelly, A., Laroche, S., and Davis, S. 2003. Activation of mitogen-activated protein kinase/extracellular signal-regulated kinase in hippocampal circuitry is required for consolidation and reconsolidation of recognition memory. J. Neurosci. 23: 5354-5360.

Marinelli, M. and Piazza, P.V. 2002. Interaction between glucocorticoid hormones, stress and psychostimulant drugs. Eur. J. Neurosci. 16: 387394.

Maroun, M. and Akirav, I. 2007. Arousal and stress effects on consolidation and reconsolidation of recognition memory. Neuropsychopharmacology 33: $394-405$.

Mattes, J.A. 1980. The role of frontal lobe dysfunction in childhood hyperkinetics. Compr. Psychiatry 21: 358-369.

Mazure, C.M. 1995. Does stress cause psychiatric illness? In Progress in Psychiatry (ed. D. Spiegel), pp. 270-298. American Psychiatric Association, Washington, DC.

Meunier, M., Bachevalier, J., and Mishkin, M. 1997. Effects of orbital frontal and anterior cingulate lesions on object and spatial memory in rhesus monkeys. Neuropsychologia 35: 999-1015.

Murphy, B.L., Arnsten, A.F.T., Goldman-Rakic, P.S., and Roth, R.H. 1996. Increased dopamine turnover in the prefrontal cortex impairs spatial working memory performance in rats and monkeys. Proc. Natl. Acad. Sci. 93: $1325-1329$.

Nader, K., Schafe, G.E., and LeDoux, J.E. 2000. The labile nature of consolidation theory. Nat. Rev. Neurosci. 1: 216-219.

Nagai, T., Takuma, K., Kamei, H., Ito, Y., Nakamichi, N., Ibi, D., Nakanishi, Y., Murai, M., Mizoguchi, H., Nabeshima, T., et al. 2007. Dopamine D1 receptors regulate protein synthesis-dependent long-term recognition memory via extracellular signal-regulated kinase $1 / 2$ in the prefrontal cortex. Learn. Mem. 14: 117-125.

Okuda, S., Roozendaal, B., and McGaugh, J.L. 2004. Glucocorticoid effects on object recognition memory require training-associated emotional arousal. Proc. Natl. Acad. Sci. 101: 853-858.

Paxinos, G. and Watson, C. 1986. The rat brain in stereotaxic coordinates, 3rd ed. Academic Press, San Diego, CA.
Phillips, A.G., Ahn, S., and Floresco, S.B. 2004. Magnitude of dopamine release in medial prefrontal cortex predicts accuracy of memory on a delayed response task. J. Neurosci. 24: 547-553.

Piazza, P.V., Rouge-Pont, F., Deroche, V., Maccari, S., Simon, H., and Le Moal, M. 1996. Glucocorticoids have state-dependent stimulant effects on the mesencephalic dopaminergic transmission. Proc. Natl. Acad. Sci. 93: 8716-8720.

Ragozzino, M.E., Detrick, S., and Kesner, R.P. 2002. The effects of prelimbic and infralimbic lesions on working memory for visual objects in rats. Neurobiol. Learn. Mem. 77: 29-43.

Rinaldi, A., Mandillo, S., Oliverio, A., and Mele, A. 2007. D1 and D2 receptor antagonist injections in the prefrontal cortex selectively impair spatial learning in mice. Neuropsychopharmacology 32: 309-319.

Rouge-Pont, F., Deroche, V., Le Moal, M., and Piazza, P.V. 1998. Individual differences in stress-induced dopamine release in the nucleus accumbens are influenced by corticosterone. Eur. J. Neurosci. 10: $3903-$ 3907.

Sara, S.J. 2000. Retrieval and reconsolidation: Toward a neurobiology of remembering. Learn. Mem. 7: 73-84.

Schafe, G.E., Atkins, C.M., Swank, M.W., Bauer, E.P., Sweatt, J.D., and LeDoux, J.E. 2000. Activation of ERK/MAP kinase in the amygdala is required for memory consolidation of pavlovian fear conditioning. $J$. Neurosci. 20: 8177-8187.

Sweatt, J.D. 2004. Mitogen-activated protein kinases in synaptic plasticity and memory. Curr. Opin. Neurobiol. 14: 311-317.

Takahata, R. and Moghaddam, B. 1998. Glutamatergic regulation of basal and stimulus-activated dopamine release in the prefrontal cortex. J. Neurochem. 71: 1443-1449.

Vijayraghavan, S., Wang, M., Birnbaum, S.G., Williams, G.V., and Arnsten, A.F. 2007. Inverted-U dopamine D1 receptor actions on prefrontal neurons engaged in working memory. Nat. Neurosci. 10: 376-384.

Weinberger, D.R., Berman, K.F., and Zec, R.F. 1986. Physiologic dysfunction of dorsolateral prefrontal cortex in schizophrenia, I: Regional cerebral blood flow evidence. Arch. Gen. Psychiatry 43: 114-124.

Williams, G.V. and Castner, S.A. 2006. Under the curve: Critical issues for elucidating D1 receptor function in working memory. Neuroscience 139: 263-276.

Zahrt, J., Taylor, J.R., Mathew, R.G., and Arnsten, A.F. 1997. Supranormal stimulation of D1 dopamine receptors in the rodent prefrontal cortex impairs spatial working memory performance. J. Neurosci. 17: 8528-8535.

Received September 28, 2008; accepted in revised form January 20, 2009. 


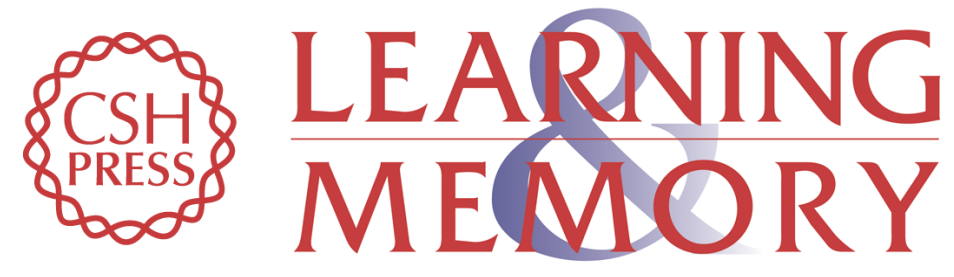

\section{Differential involvement of dopamine D1 receptor and MEK signaling pathway in the ventromedial prefrontal cortex in consolidation and reconsolidation of recognition memory}

Mouna Maroun and Irit Akirav

Learn. Mem. 2009, 16:

Access the most recent version at doi:10.1101/lm.1245009

References This article cites 50 articles, 13 of which can be accessed free at: http://learnmem.cshlp.org/content/16/4/243.full.html\#ref-list-1

License

Email Alerting Receive free email alerts when new articles cite this article - sign up in the box at the Service top right corner of the article or click here. 